\title{
Data and optimization model of an industrial heat transfer station to increase energy flexibility
}

\author{
Thomas Kohne*, Lukas Theisinger, Jan Scherff and Matthias Weigold \\ From The 10th DACH+ Conference on Energy Informatics \\ Virtual. 13-17 September 2021
}

\author{
${ }^{*}$ Correspondence: \\ t.kohne@ptw.tu-darmstadt.de \\ Institute of Production \\ Management, Technology and \\ Machine Tools, Technical University \\ of Darmstadt, Otto-Berndt-Straße 2, \\ 64287 Darmstadt, Germany
}

\begin{abstract}
Nations and companies are forced to reduce $\mathrm{CO}_{2}$ emissions and decelerate global warming. In this development, the transition of the heating sector is still in its infancy despite the relatively large share of thermal energy in the total energy consumption. Industrial companies can contribute significantly to reduce $\mathrm{CO}_{2}$ emissions by using waste heat through connecting their industrial energy supply system (IESS) to a district heating system (DHS). This paper focuses on emission reduction potential of an (industrial) heat transfer station (HTS) regarding energy flexibility and sector coupling required for the successful integration of industrial waste heat. To optimize the operating behaviour of the HTS, a data and optimization model is integrated into a digital twin (DT) based on reference architecture model for industry 4.0 (RAMI4.0). Within the DT, the information, functional and business layer are modeled. The effects of operating the HTS supported by central modules of the DT are evaluated on one year's data of an IESS of a real industrial site. The results show a potential operating cost reduction by $6 \%$ for the IESS and increases in profits of $1.3 \%$ for the DHS. Scope 2 emissions can be reduced by $25 \%$ for the IESS and $180 \%$ for the DHS respectively, strongly depending on emission factors and allocation methods.
\end{abstract}

Keywords: Industrial energy supply systems, District heating systems, Smart grids, Heat transfer station, Digital twin, Optimization

\section{Introduction}

Nations and companies are forced to reduce $\mathrm{CO}_{2}$ emissions and decelerate global warming, e. g. by increasing energy efficiency and the share of renewable energy production (Masson-Delmotte et al. 2018). In this development, the transition of the heating sector is still in its infancy despite the relatively large share of thermal energy in the total energy consumption. In Germany, the share of thermal energy in the industrial sector is $70 \%$, in the residential sector $90 \%$, respectively (Anwendungsbilanzen zur credit to the original author(s) and the source, provide a link to the Creative Commons licence, and indicate if changes were made. The images or other third party material in this article are included in the article's Creative Commons licence, unless indicated otherwise in a credit line to the material. If material is not included in the article's Creative Commons licence and your intended use is not permitted by statutory regulation or exceeds the permitted use, you will need to obtain permission directly from the copyright holder. To view a copy of this licence, visit http://creativecommons.org/licenses/by/4.0/. 
Energiebilanz Deutschland 2020). For the heat-related energy transition different pathways can be outlined: electrification, co-generation and district heating as well as power to gas (Kavvadias et al. 2019). Sector coupling and electrification of the heating sector can contribute to emission reduction by integrating renewable energy sources (RES) as well as waste heat (Thomaßen et al. 2021). Here, DHS can help to overcome local surpluses and shortcomings to enable a more flexible integration.

Industrial companies can contribute significantly to reduce $\mathrm{CO}_{2}$ emissions by using waste heat through connecting their IESS to a DHS, e. g. within densely populated areas (Pelda et al. 2020). The extend to which sector-coupling and waste heat utilization are possible strongly depends on temperature levels: for applications that can utilize waste heat up to $100^{\circ} \mathrm{C}$, the potential in Germany is about $56 \mathrm{PJ} / \mathrm{a}$; for use up to $70^{\circ} \mathrm{C}$ its $82 \mathrm{PJ} / \mathrm{a}$ and for up to $35^{\circ} \mathrm{C}$ its $127 \mathrm{PJ} / \mathrm{a}$, respectively (Brückner 2016).

To couple several thermal networks and utilize waste heat, a complex HTS consisting of heat exchangers (HEX), energy converters, heat storage (HS) and a thermal circuit to integrate heat is necessary. For a flexible coupling and beneficial operation of such complex subsystems, characteristics of surrounding networks or relevant temperature levels need to be taken into account for the operation of HTS (Ancona et al. 2015). Depending on the HTS topology, integrated energy converters like heat pump (HP) or immersion heater $(\mathrm{IH})$ enable coupling with the power grid. Here, variable (thermal) operating conditions and a volatile renewable energy supply require an operation optimization to maximize revenues and minimize emissions (Kohne et al. 2021).

The operation optimization itself requires a profound data basis. Rising digitization and standardization offer the opportunity to improve overall transparency and operation in industrial production sites and processes (Posselt 2016). Especially for the integration of complex interconnecting systems such as HTS, a digital representation in the form of a DT (Stark and Damerau 2019) is necessary. To develop and integrate such cyber-physical systems in industrial applications, the RAMI4.0 was developed as a fundamental architecture for standardization in industry 4.0 (DIN - Deutsches Institut für Normung e.V. 2016).

This paper focuses on emission reduction potential of an HTS regarding energy flexibility, sector coupling and waste heat utilization by connecting an IESS with a DHS. To enable an autonomous, optimized control of the HTS, a data and optimization model is implemented into a digital representation of the system. After a brief introduction of the related work, the technical and digital system design is presented, followed by modeling of central modules of the DT. The work is then tested and evaluated on a specific use case.

\section{Related work}

Existing research on integrating industrial waste heat or connecting IESS and DHS mainly focuses on a general evaluation. While Marguerite et al. (2017) examines a specific use case in Vienna to technically integrate low exergy industrial waste heat, Zhang et al. (2020) presents a mathematical optimization approach to connect an industrial site and a DHS regarding economic objectives. In Ancona et al. (2015), a general concept and layouts of bidirectional HTS for generic prosumers in DHS are presented. Here, the thermal prosumer is integrated into the DHS via HEX for consumption and supply. This concept is technically implemented and experimentally evaluated in Pipiciello et al. (2021). For a bidirectional integration of prosumers in DHS, Rosemann et al. (2017) focuses on general 
operating strategies, presenting four main strategies to combine a DHS, a solar thermal system and a heat consumer. In Kohne et al. (2021) the explained aspects of integrating low exergy industrial waste heat, connecting IESS and DHS bidirectionally as well as developing general operating strategies are combined into a hollistic technical concept of an HTS.

Although Kohne et al. (2021) presents a general concept for a DT of an HTS, none of the listed approaches consider a digital representation of an HTS in detail. However, such complex and interconnecting technical systems can be translated as DT into the industrial internet of things (IIoT). In the five dimensional digital twin (5D-DT) model (Tao et al. 2019), DT consist of the physical and virtual entity, a data model and services as well as the necessary connections. Furthermore, Stark and Damerau (2019) defines general characteristics of DT for production systems. To improve the operating behaviour of technical systems by DT, Ashtari Talkhestani et al. (2019) describes an intelligent DT. As explained, the RAMI4.0 offers an architecture to integrate physical entities into the IIoT. Based on RAMI4.0 and the 5D-DT, Steindl et al. (2020) develops a generic digital twin model (GDTM) for energy systems.

In this work, an energy flexible operation can be enabled for the interconnecting technical system as described in Kohne et al. (2021). The technical system and thus the data and optimization model integrate and extend several approaches of the related work such as:

- bidirectional heat exchange,

- integration of low exergy waste heat,

- several thermal networks of the IESS,

- sector coupling with the electric grid,

- economic and ecological objectives.

Moreover, the GDTM is transferred to a data and optimization model to holistically represent the energy flexibility of connecting DHS and IESS. Here, the business, functional and information layer are focused and expanded to integrate an optimization model which takes operating states of surrounding networks into account. Furthermore, economic and ecological objectives are integrated into the data and optimization model and thus into the GDTM, providing necessary information for optimized control. In addition, a prototypical implementation on the base of a real industrial site is presented to proof the functionality of key aspects.

\section{System design}

In this section, the overall system design of the HTS, the IESS and the DHS as well as its energy flexibility potential is presented. Moreover, a digital representation for flexible control of the HTS is outlined.

\section{Technical system and energy flexibility}

To maximize energy flexibility and integrate different waste heat sources, the HTS connects a DHS and different heating and cooling networks of an IESS as in Kohne et al. (2021). Typical IESS supply several heat consumers, mainly divided into production processes and space heating. As these require different temperature levels, some industrial sites operate heating networks with different flow temperatures, e. g. a high temperature 
heating network (HNHT) for production processes and an low temperature heating network (HNLT) for space heating. Moreover, IESS can include a cooling network (CN) e. g. for cooling production machines or energy converters.

Within the IESS, the HTS can be regarded as an autonomous operating system containing a thermal circuit with a bidirectional heat exchange at the interface between DHS and IESS. By that, thermal energy of an HNHT of the IESS can be used either to supply an HNLT or the DHS. Likewise, thermal energy from the DHS can be used to supply an HNLT. The flow temperature of the HTS must be adapted depending on the required temperatures of the connected networks. Moreover, to integrate a $\mathrm{CN}$ and its low exergy waste heat, HP technology can be integrated, e. g. in the return flow of the HTS. This power to heat flexibility can be increased by the integration of $\mathrm{HS}$ and $\mathrm{IH}$.

Figure 1 illustrates the overall system and its possible interactions. Here, the energy converters of the IESS and the DHS are displayed as a conventional system consisting of combined heat and power (CHP) and (condensing) boiler (B). For cooling supply in the $\mathrm{CN}$ of the IESS, active and passive cooling can be implemented depending on required flow temperatures. If the required temperatures are higher than the environmental temperatures, passive cooling can be used efficiently, e. g. by a CT. The presented work mainly focuses on DHS with flow temperatures between 50 and $100{ }^{\circ} \mathrm{C}$ which can be connected bidirectionally with an IESS. For a summary of different typologies of DHS we refer to Lund et al. (2014).

The presented HTS enables energy flexibility in two ways: Firstly, the multiple options of thermal energy exchange between different heating networks. Depending on the thermal energy demand of the industrial site and the consumers in the DHS, thermal energy can be shifted between the heating networks. Thus, different efficiency levels and emission reduction potential of the energy converters at both sites can be optimized. Secondly, by integrating power to heat technologies such as HP and IH, energy procurement can be shifted between different final energy sources and low exergy waste heat can be inte-

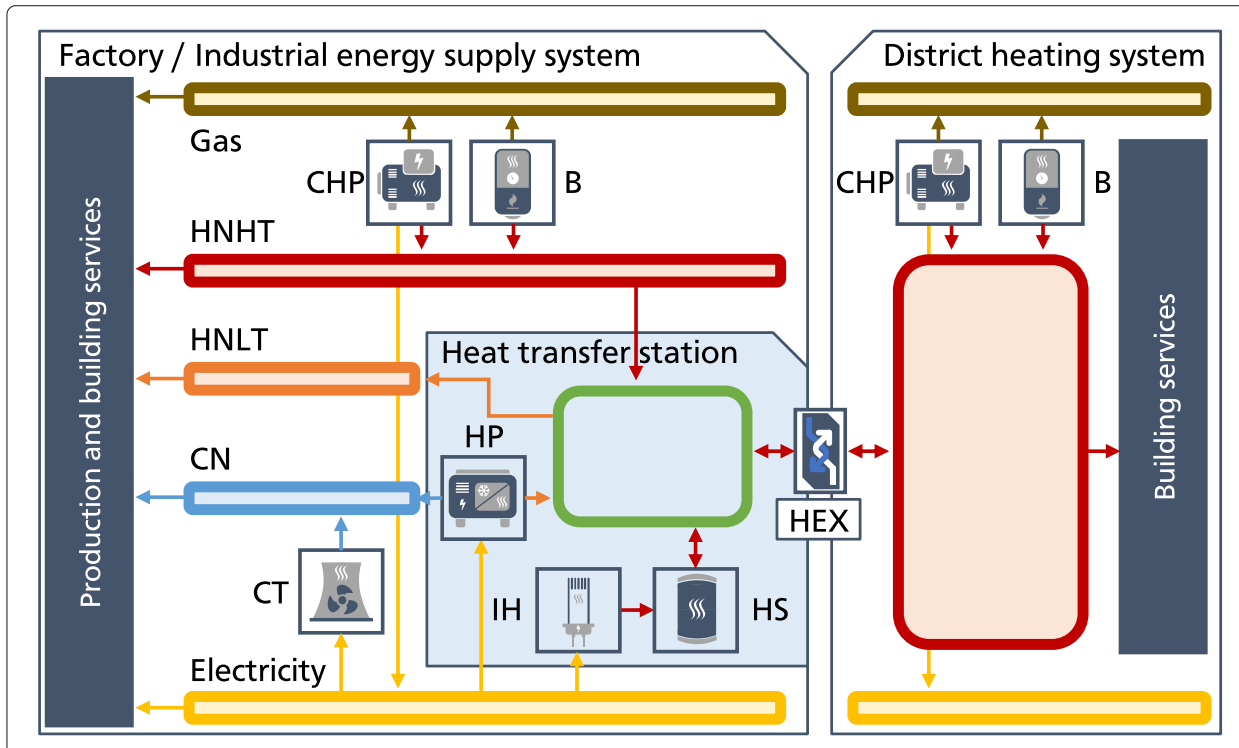

Fig. 1 Industrial heat transfer station as an autonomous subsystem of an industrial energy supply system, flexibly connecting the industrial site with the district heating system 
grated. The resulting electrical power flexibility can be used in real time pricing or for system services as described in Dong and Zou (2015).

\section{Digital representation}

To operate the HTS energy efficiently and flexibly, temperature levels and interdependent efficiencies as well as external and internal price and emission must be considered. Consequently, a digital representation can enable an optimized and flexible control of such a complex interconnecting system. Depending on the degree of digitization within the industrial site, its energy management system (EMS) can be connected to the digital representation of the HTS. The digital representation framework applied in this work is based on Steindl et al. (2020) which integrates DT into the RAMI4.0. The embedding of the DT into RAMI4.0 offers a suitable structure to describe and order the modules of a DT. The concept is adapted for optimized control including a two-stage control approach, especially considering the different connections to the surrounding systems as well as an extended economic and ecological balancing. Whereas Steindl et al. (2020) present a datadriven modeling approach, within this paper a white-box modeling approach is utilized with regard to the simulation model. This allows for adjustments of the HTS structure without being dependent on extensive operating data. By that, the presented DT can be utilized along the RAMI4.0 life cycle axis, from development (e. g. dimensioning) towards usage (e. g. optimized control).

Figure 2 shows the different layers of the digital representation. For a detailed description of the lower three layers (asset, integration and communication) we refer to Steindl

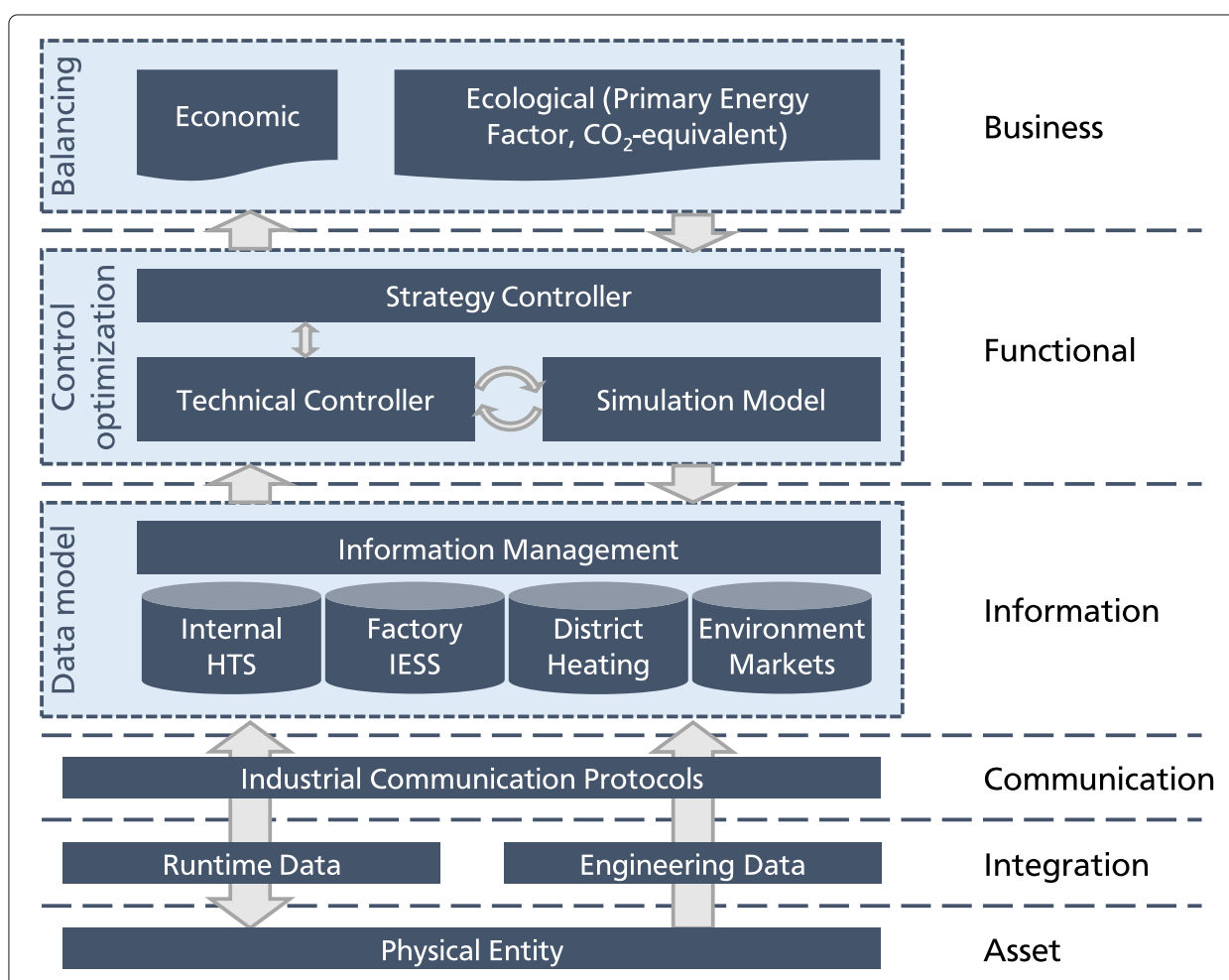

Fig. 2 Digital twin of the industrial heat transfer station integrated into the layer system of the RAMI4.0 based on Steindl et al. (2020) 
et al. (2020) extended by an information flow from the information layer to the asset representing possible control signals of an optimized operating strategy as in Ashtari Talkhestani et al. (2019). In the following, the upper three layers (information, functional and business) are introduced and modelled.

Information layer Besides the internal runtime and engineering data of the HTS, a DT needs corresponding data of the surrounding systems IESS and DHS in the form of unprocessed data or key perfomance indicators (KPI). In an information management, the different kind of data are processed and integrated into a holistic data model.

Functional layer As described in Steindl et al. (2020), the functional layer integrates services into the DT. To enable a flexible operation considering technical, economical and ecological data, a two stage control service is introduced. The strategy controller processes market data and technical KPI to optimize a schedule while the technical controller enables a higher frequented interaction with the technical system. The simulation model is used for testing new control strategies and improved monitoring.

Business layer Within the business layer, the overarching objective is defined with which the DT should support the physical entity. Furthermore, the degree of fulfilment of the defined objective is evaluated by balancing economic or ecological quantities e. g. by considering scope 1 and 2 emissions (World Resources Institute and World Business Council for Sustainable Development 2004). Thus, the business layer is directly connected to the EMS of the industrial site.

\section{Modeling}

In this section, the data model (information layer), the control optimization (functional layer) and the economical and ecological balancing (business layer) are presented to optimize the energy flexible operation of the HTS.

\section{Data model}

To enable a flexible operation of the HTS, data need to be gathered, processed and stored. Therefore, a data model as shown in Fig. 3 is set up upon the basis of data interfaces, data analytics as well as a data storage. Data interfaces allow access to data of external systems like energy markets, weather services, the DHS or the EMS of the IESS e. g. via application programming interface (API). Data analytics allow for deeper insights into gathered data e. g. by linking different data to KPI or by applying more complex methods like data mining to detect patterns and trends. With regard to the IESS and HTS, this can be utilized to predict future thermal energy demands as well as identifying dependencies between efficiencies, temperature levels and thermal energy demands e. g. via regression analysis. For that, an efficient and reliable access to runtime and engineering data must be guaranteed by the data storage. Within the data storage, processed and unprocessed data is stored in a defined format to ensure its availability. By that, historical data can be accessed on demand e. g. for data analytics. 


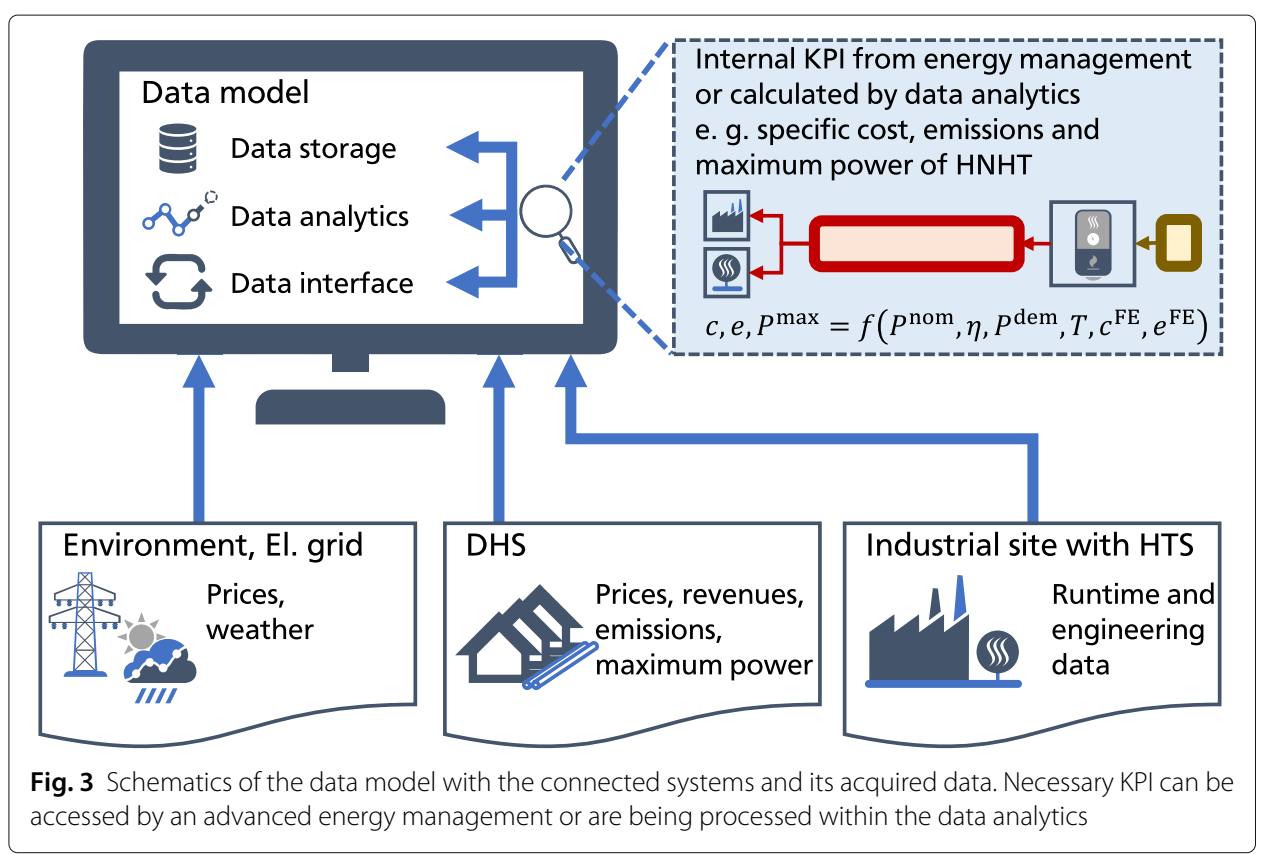

Due to the functional segregation of the data interface, analytics and storage the data model allows for an optimal interoperability. Depending on the specific application, the portrayed interfaces can be complemented on demand just as data analytics may show different levels of detail. As the KPI are a central feature of the data model, they exhibit a standardized pattern, e. g. specific prices or costs. Similarly, the KPI can be flexibly adjusted to the requirements of their application. With regard to resilience, missing or erroneous data can be compensated, e. g. via interpolation or boundaries.

The data model must process different kind of data depending on the data source (Fig. 3), e. g. environmental data such as weather conditions or energy prices for electricity or gas. Dependent on the electricity market, the price can be static or varying such as in dynamic pricing models. To operate the connection to the DHS, the data model of the HTS needs to incorporate thermal energy prices and revenues for procured or supplied thermal energy. Prices can be static but also variable, e. g. dependent upon temperature levels. Application specific characteristics must be considered by the data model as well. With regard to electricity, different taxes and remunerations must be taken into account, supporting key functionalities of the business layer. Additionally, data on emissions of the DHS and the maximal procured or supplied thermal energy for each time step must be known. In case of the HTS itself and the IESS these data can be technical runtime data such as network temperatures or thermal and electric power of HEX, energy converters and consumers. Moreover, engineering data can include nominal power or (part load) efficiencies of energy converters. To operate the energy converters, storage and HEX of the HTS the data model must process runtime and engineering data to derive KPI at its technical boundaries which is exemplary shown in Fig. 3. Here, nominal power $P^{\text {nom }}$ and efficiencies $\eta=\frac{P^{\text {th }}}{P^{\text {nom }}}$ of energy converters, the thermal power demand $P^{\text {dem }}$, the network temperature $T$ and final energy cost $c^{\mathrm{FE}}$ and emissions $e^{\mathrm{FE}}$ of a thermal network are used 
to derive the maximum power $P^{\max }$ as well as specific internal cost and emissions at the system boundary (HEX) of the HTS. The calculation of the latter is based on Eqs. 1 and 2 where all final energy carries must be considered.

$$
\begin{aligned}
\mathrm{c}_{t} & =\frac{\sum_{f \in \mathrm{F}} \mathrm{c}_{f, t}^{\mathrm{FE}} \cdot \mathrm{P}_{f, t}^{\mathrm{FE}}}{\mathrm{P}_{t}^{\mathrm{dem}}} \\
\mathrm{e}_{t} & =\frac{\sum_{f \in \mathrm{F}} \mathrm{e}_{f, t}^{\mathrm{FE}} \cdot \mathrm{P}_{f, t}^{\mathrm{FE}}}{\mathrm{P}_{t}^{\mathrm{dem}}}
\end{aligned}
$$

As portrayed in Eq. 3, the calculation of the specific factors can be rather extensive. Here, the specific internal costs of the HNHT is calculated based on the gas consumption, electricity generation, the associated costs and rewards as well as the proportion of own consumption $\alpha$. If the IESS has an advanced EMS, these derived internal KPI can be delivered by the EMS.

$$
\mathrm{c}_{t}^{\mathrm{HNHT}}=\frac{\mathrm{c}_{t}^{\text {gas }} \cdot\left(\mathrm{P}_{t}^{\mathrm{gas}, \mathrm{CHP}}+\mathrm{P}_{t}^{\text {gas, } \mathrm{B}}\right)-\left(\alpha_{t} \cdot \mathrm{c}_{t}^{\mathrm{el}}+\left(1-\alpha_{t}\right) \cdot \mathrm{r}_{t}^{\mathrm{el}}\right) \cdot \mathrm{P}_{t}^{\mathrm{el}, \mathrm{CHP}}}{\mathrm{P}_{t}^{\mathrm{dem}}}
$$

\section{Control optimization}

The data model of the information layer can be used for monitoring and optimized control in the functional layer. To consider market data as well as reliably controlling the technical system, a two stage control approach is proposed (Fig. 4). Based on data from the data model such as day ahead prices, thermal energy cost and emissions, the strategy controller uses mixed integer linear programming (MILP) to calculate a schedule for the HTS, e. g. one day in advance. The task of the technical controller is the fulfilment of the schedule interacting real time with the physical entity or simulation model. The simula-

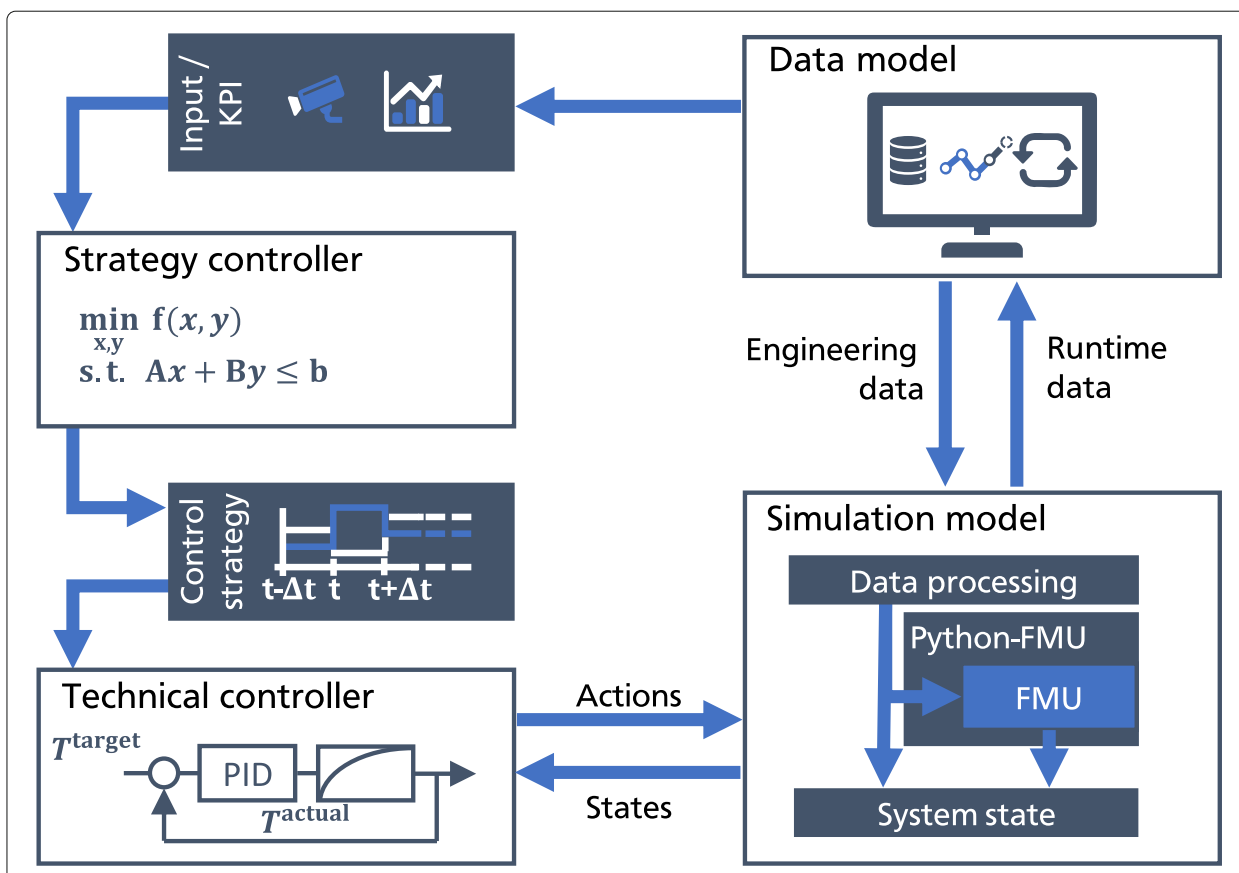

Fig. 4 Two stage control approach of the heat transfer station with connection to the data and simulation model. The simulation model is integrated as a functional mock-up unit 
tion model is integrated as a functional mock-up unit (FMU) and calculates states of the technical system based on the data model.

The MILP model of the strategy controller calculates the thermal power for each time step for the different HEX as well as HP and IH by minimizing its internal cost (min $C^{\mathrm{HTS}}$ ). In the following the main equations (power balances) of the MILP model are outlined. Equation 4 describes the thermal power balance of the HTS for each time step $t$ including every HEX as well as the thermal power of the HP $P_{t}^{\text {th,HP }}$ and the HS $P_{t}^{\text {th,HS }}$.

$$
0=P_{t}^{\mathrm{th}, \mathrm{HP}}+P_{t}^{\mathrm{th}, \mathrm{HNHT}}-P_{t}^{\mathrm{th}, \mathrm{HNLT}}+P_{t}^{\mathrm{th}, \mathrm{in}, \mathrm{DHS}}-P_{t}^{\mathrm{th}, \mathrm{out}, \mathrm{DHS}}+P_{t}^{\mathrm{th}, \mathrm{HS}}
$$

The thermal power of the HP is limited by its efficiency (coefficient of performance $(\mathrm{COP})) \eta_{t}^{\mathrm{HP}}$, nominal power $\mathrm{P}^{\mathrm{el}, \mathrm{max}, \mathrm{HP}}$ and the maximum cooling demand $\mathrm{P}_{t}^{\mathrm{c}, \mathrm{max}, \mathrm{HP}}$ (Eqs. 5-8). The efficiency of the HP can be set either time dependent or constant.

$$
\begin{aligned}
& P_{t}^{\mathrm{th}, \mathrm{HP}}=P_{t}^{\mathrm{el}, \mathrm{HP}}+P_{t}^{\mathrm{th}, \mathrm{c}, \mathrm{HP}} \\
& P_{t}^{\mathrm{th}, \mathrm{HP}}=P_{t}^{\mathrm{el}, \mathrm{HP}} \cdot \eta_{t}^{\mathrm{HP}} \\
& P_{t}^{\mathrm{th}, \mathrm{c}, \mathrm{HP}} \leq \mathrm{P}_{t}^{\mathrm{c}, \mathrm{max}, \mathrm{HP}} \\
& P_{t}^{\mathrm{el}, \mathrm{HP}} \leq \mathrm{P}^{\mathrm{el}, \mathrm{max}, \mathrm{HP}}
\end{aligned}
$$

The IH is part of the HS (Eqs. 9-10) and limited by its efficiency $\eta_{t}^{\mathrm{IH}}$ and nominal power $\mathrm{P}^{\mathrm{el}, \mathrm{max}, \mathrm{IH}}$.

$$
\begin{aligned}
& P_{t}^{\mathrm{th}, \mathrm{IH}}=P_{t}^{\mathrm{el}, \mathrm{IH}} \cdot \eta_{t}^{\mathrm{IH}} \\
& P_{t}^{\mathrm{el}, \mathrm{IH}} \leq \mathrm{P}^{\mathrm{el}, \mathrm{max}, \mathrm{IH}}
\end{aligned}
$$

The thermal energy which can be stored in the $\mathrm{HS} Q_{t}^{\mathrm{HS}}$ has a maximum capacity $\mathrm{Q}^{\max , \mathrm{HS}}$ (Eqs. 11-12)

$$
\begin{aligned}
& Q_{t}^{\mathrm{HS}}=Q_{t-1}^{\mathrm{HS}}+\left(P_{t}^{\mathrm{th}, \mathrm{HS}}+P_{t}^{\mathrm{th}, \mathrm{IH}}\right) \cdot \Delta \mathrm{t} \\
& 0 \leq Q_{t}^{\mathrm{HS}} \leq \mathrm{Q}^{\mathrm{max}, \mathrm{HS}}
\end{aligned}
$$

The thermal power of each HEX is limited by the KPI of the surrounding systems especially the maximum power $\mathrm{P}^{\text {th, } m a x, H E X}$ (Eq. 13). To decide whether thermal power is supplied by the DHS $P_{t}^{\text {th,in,DHS }}$ or fed into the DHS $P_{t}^{\text {th,out,DHS }}$ a distinction has to be integrated with the binary variable $\delta_{t}^{\text {in,DHS }}$ (Eqs. 14-15).

$$
\begin{aligned}
& 0 \leq P_{t}^{\mathrm{th}, \mathrm{HEX}} \leq \mathrm{P}^{\mathrm{th}, \text { max,HEX }} \\
& 0 \leq P_{t}^{\mathrm{th}, \mathrm{in}, \mathrm{DHS}} \leq \mathrm{P}^{\mathrm{th}, \mathrm{max}, \mathrm{in}, \mathrm{DHS}} \cdot \delta_{t}^{\mathrm{in}, \mathrm{DHS}} \\
& 0 \leq P_{t}^{\mathrm{th}, \text { out,DHS}} \leq \mathrm{P}^{\mathrm{th}, \text { max }, \text { out,DHS }} \cdot\left(1-\delta_{t}^{\mathrm{in}, \mathrm{DHS}}\right)
\end{aligned}
$$

Besides the thermal balance, the electric power demand of the HTS $P_{t}^{\mathrm{el}, \mathrm{HTS}}$ is calculated in the electric power balance (Eq. 16). To consider peak loads, the electric power of the HTS is added up with the electric power demand of the industrial site $P_{t}^{\mathrm{el}, \text { Factory }}$ and the change of the peak load $P^{\text {el,deltaPeak }}$ is calculated compared to the former peak $P^{\text {el,currentPeak }}$.

$$
\begin{aligned}
& P_{t}^{\mathrm{el}, \mathrm{HTS}}=P_{t}^{\mathrm{el}, \mathrm{IH}}+P_{t}^{\mathrm{el}, \mathrm{HP}} \\
& P_{t}^{\mathrm{el}, \mathrm{HTS}}+P_{t}^{\mathrm{el}, \text { Factory }}-P^{\mathrm{el}, \text { currentPeak }} \leq P^{\mathrm{el}, \mathrm{deltaPeak}} \\
& 0 \leq P^{\mathrm{el}, \text { deltaPeak }}
\end{aligned}
$$

Equation 19 calculates the total scope $1+2$ emissions of the HTS $E^{\text {HTS }}$ as internal values depending on the thermal power shifted between the different thermal networks through 
the HEX or the HP as well as the emissions from the electric power procurement $E_{t}^{\mathrm{el}}$. The emissions of each time step are dependent on the thermal power $P_{t}$ and the specific emissions of each thermal energy source $\mathrm{e}_{t}$ (Eq. 20).

$$
\begin{aligned}
& E^{\mathrm{HTS}}=\sum_{t \in \mathrm{T}}\left(E_{t}^{\mathrm{HNHT}}-E_{t}^{\mathrm{HNLT}}+E_{t}^{\mathrm{in}, \mathrm{DHS}}-E_{t}^{\mathrm{out}, \mathrm{DHS}}+E_{t}^{\mathrm{el}}\right) \\
& E_{t}=\mathrm{e}_{t} \cdot P_{t} \cdot \Delta \mathrm{t}
\end{aligned}
$$

The overall cost $C^{\mathrm{HTS}}$ of the HTS for the calculated time horizon include cost for thermal and electric energy, electric peak power as well as cost for $\mathrm{CO}_{2}$ emissions (Eq. 21). The cost for $\mathrm{CO}_{2}$ emissions can be either set to scope 1 (direct) or scope $1+2$ (direct+indirect) emissions dependent on the specific optimization goal. The specific cost $c_{t}$ for each term are either external cost such as day ahead prices of the electricity market or thermal energy cost of the DHS as well as internal prices such as cost for thermal energy supply in the HNHT (Eq. 22). Moreover, revenues $R$ of the HTS are included such as the supply of thermal energy for the DHS or CN calculated by specific revenues $\mathrm{r}_{t}$ (Eq. 23).

$$
\begin{aligned}
C^{\mathrm{HTS}} & =\sum_{t \in \mathrm{T}}\left(C_{t}^{\mathrm{HNHT}}+C_{t}^{\mathrm{DHS}}+C_{t}^{\mathrm{el}}+C_{t}^{\mathrm{CO} 2}\right)+C^{\text {Peak }} \\
& -\sum_{t \in \mathrm{T}}\left(R_{t}^{\mathrm{HNLT}}-R_{t}^{\mathrm{DHS}}-R_{t}^{\mathrm{CN}}\right) \\
C_{t} & =\mathrm{c}_{t} \cdot P_{t} \cdot \Delta \mathrm{t} \\
R_{t} & =\mathrm{r}_{t} \cdot P_{t} \cdot \Delta \mathrm{t}
\end{aligned}
$$

All of the equations with index $t$ are calculated for the time horizon $T$ of the MILP model which can be set individually. In the use case, the MILP based on the described power balances is used which are parameterized from the data model. To improve the overall MILP model also temperature dependencies as described in Kohne et al. (2019) can be integrated.

The technical controller receives the schedule generated by the strategy controller as an input. Besides fulfilling the schedule, the technical controller must also ensure that temperature requirements are met to operate the technical system sufficiently. Therefore, the technical controller interacts constantly with the simulation model or physical entity and uses PID control elements to adjust and calculate control signals for the subsystems of the HTS such as energy converters and pumps. Here, runtime data from the HTS and the surrounding systems are necessary. The control signals of the energy converters can be calculated by Eq. 24 where $e$ typically represents the difference between target and actual temperature.

$$
u=K_{p} * e+K_{i} \int_{0}^{t} e d t+K_{d} \frac{d}{d t} e
$$

The simulation model must contain physical equations of the HTS and may contain ones of the surrounding systems evaluate control signals and the economic and ecological balancing. Those physical equations of the HTS as well as the engineering data of the data model can be utilized to generate estimates for the PID parameters, e. g. by applying the method presented in Chien (1972). By that, the users effort for PID parametrization is minimized. 


\section{Economic and ecological balancing}

The DT of the HTS must be connected to the business logic of the IESS and its EMS to determine and evaluate its operating behaviour. The overall balancing can be divided into economic and ecological quantities. Within the IESS, the ecological balancing can be achieved by assigning specific emission factors to energy flows. Depending on necessary level of detail, scope 1 and scope 2 emissions as well as primary energy demand for DHS are common assessment criteria (DIN Deutsches Institut für Normung e.V. 2018). As demonstrated in Kohne et al. (2021) the aforementioned criteria are strongly influenced by the operating conditions within the thermal networks. Therefore, the business layer must be provided with information about the current utilisation level and efficiencies of the energy converters of the the HTS. Moreover, purchased as well as supplied thermal and electric energy is of key interest. Especially with regard to electric energy,

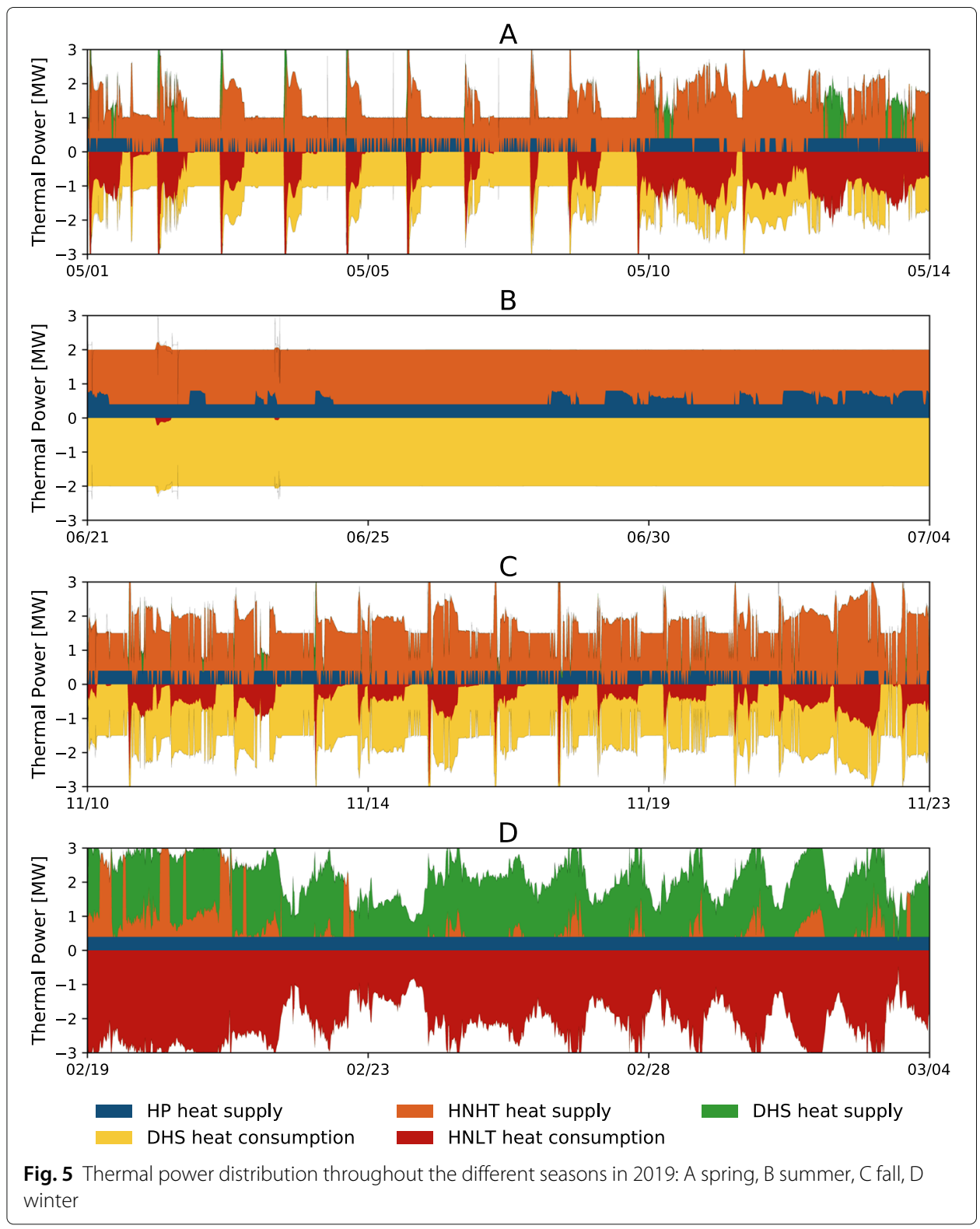


the distinction between purchase and supply is of key interest as applied. Therefore, the balancing requires detailed information about the IESS via the EMS. Similar to the ecological balancing, the economic balancing can be achieved by assigning specific prices/cost to energy flows. Depending on the energy procurement of the IESS, those prices can be static or dynamic. Additionally to the energy procurement, the business layer may support regulatory requirements of the IESS with regard to the accounting of energy taxes and fees.

\section{Simulation}

Within the following section, key functionalities of the presented digital representation are demonstrated. For this purpose, a physical simulation model of the HTS and the surrounding systems is developed in the object-oriented modeling language Modelica. The model is then translated as a FMU and embedded within a Python framework presented in Kohne et al. (2020). The Python framework allows a time-discrete interaction with the physical simulation model, which was extended by the two stage optimization approach. With regard to data management, the object oriented approach of the framework allows for an straightforward implementation of the described data model. Here, in addition to the calculation of specific factors, initial approaches for data analytics like regression analysis where implemented.

\section{Use case}

The effects of operating the HTS supported by central modules of the DT are evaluated on the basis of an IESS of a real industrial site which is already connected to a DHS in a inflexible manner, allowing only a constant heat supply into the DHS. The IESS and DHS inherit the general structure presented in Fig. 1. Regarding the IESS, the HNHT exhibits a flow temperature of about $115^{\circ} \mathrm{C}$ mainly supplying production processes, the HNLT of about $90^{\circ} \mathrm{C}$ supplying building services. The DHS supplies residential buildings with a flow temperature of about $100^{\circ} \mathrm{C}$. The selected use case is representative for IESS as it exhibits a conventional, gas-based heating supply structure as well as a typical topology with separated thermal networks for heating and cooling applications (Kleinertz et al. 2019). Furthermore, the temperature levels of the thermal networks are characteristic for the manufacturing industry. The hydraulic topology of the HTS is set up as presented in Kohne et al. (2021) consisting of four HEX, a HS as well as a HP and IH for sector coupling purposes.

\section{Results}

Since the thermal energy demand of IESS and DHS varies throughout the year, a simulation study consisting of four different scenarios (winter, spring, summer and fall) was conducted. To evaluate the effect of operating the HTS, for each of those scenarios a baseline scenario as well as an optimized scenario were simulated over a time horizon of two weeks. During the baseline scenarios the HTS is not used to exchange thermal energy between the IESS and the DHS. During the optimized scenarios a schedule is generated by the optimization model for which a time 24 hours with a 15 minute period time is set and subsequently applied to the HTS. The simulation results are then evaluated regarding economic and ecological criteria. Within the evaluation, the HTS is considered to be 
a part of the IESS and therefore the industrial site. By that, all revenues and costs which are related to the operation of the HTS are credited to the IESS.

As illustrated in Fig. 5 the presented optimization model is able to plan a flexible operation of the HTS which can be applied to the physical simulation model via the technical controller. The data model generates enough insights for the optimization model to take into account variable operation conditions throughout the year. Thus, the optimization model is able to plan an optimized combination of the available thermal energy sources. During the transitional periods (spring and fall) the schedule is characterized by a heterogeneous thermal energy supply. Here, the DHS occasionally operates as heat source or heat sink. During summer, no heating demand with regard to HNLT is present resulting in a sole heat supply into the DHS via HNHT and HP. On the contrary, during winter HNLT exhibits a high heat demand resulting in a combined heat supply through HNHT, HP and DHS. The degree of freedom regarding the operational optimization is expanded by the energy flexibility of the HTS, which is clarified in Fig. 6. Firstly, by enabling a flexible thermal energy heating networks. Therefore, the DHS can be utilized as a heat source or sink for the IESS, e. g. depending on the current thermal load and therefore heat price within the IESS. Likewise, by utilizing flexible power to heat technologies such as HP or $\mathrm{IH}$ and therefore reacting to energy price fluctuations.

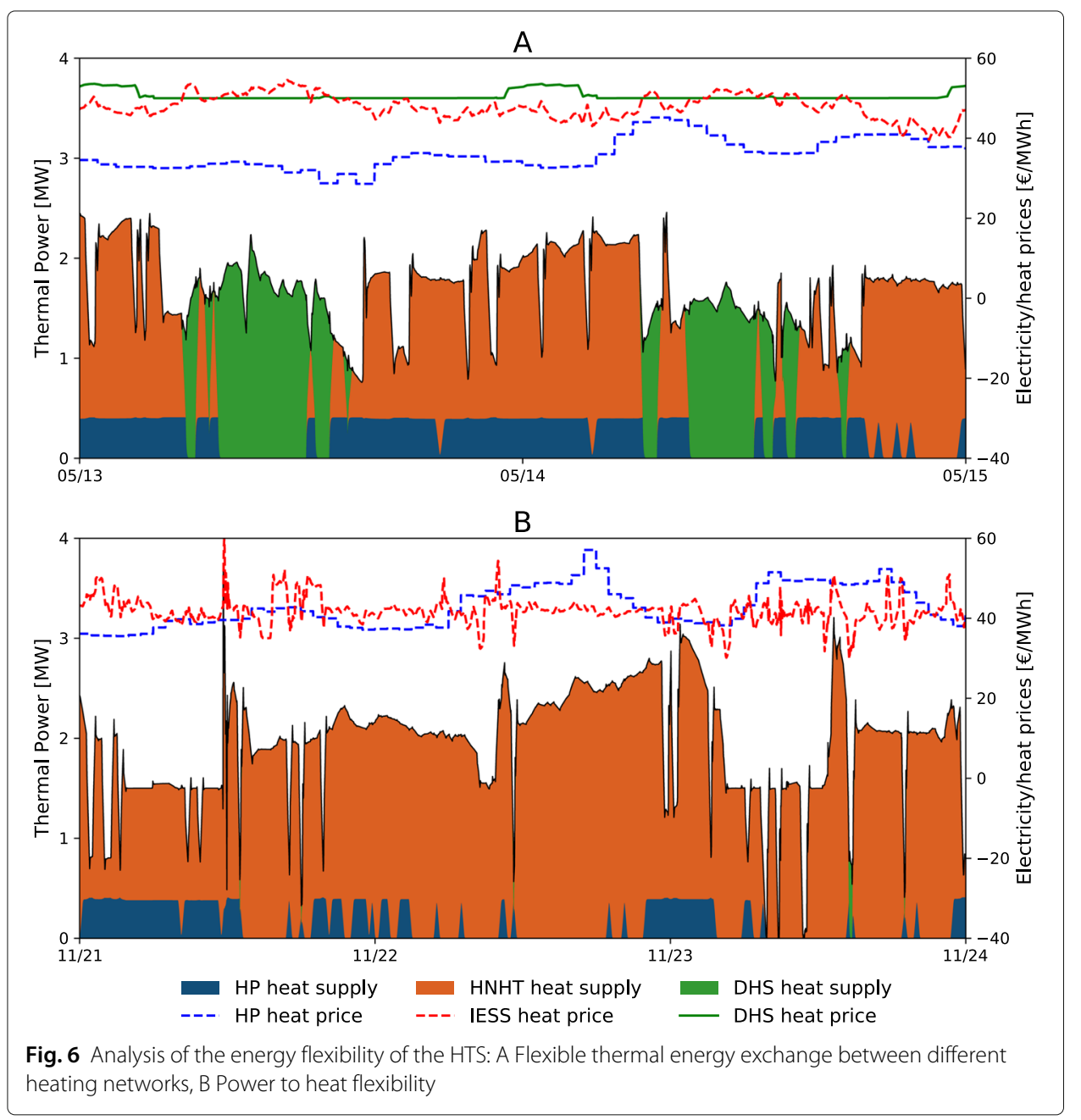


The evaluation of the simulation results in Table 1 clarifies that within all scenarios the operation of the HTS generates an economic benefit for both stakeholders, the IESS and DHS. With regard to economic objectives, only operating expenses are taken into account. Capital costs are not assessed within the analysis. Evaluating the IESS, the operation of the HTS leads to a mean reduction of operating expenses of about $6 \%$. On one hand the B can be substituted with cheaper thermal energy from the HP and DHS during thermal energy demand. On the other hand, the HTS allows for an increase of the CHP utilization by selling heat to the DHS during low thermal energy demand. The increase of the CHP utilization furthermore decreases the electric grid consumption of the IESS. With regard to the DHS the HTS can raise the mean profit by $1.3 \%$ either by offering less expensive thermal energy or by increasing heat sales.

Considering scope 1 emissions, the operation of the HTS does not lead to a ecological benefit on an overall level. This is due to the fact that the HTS couples conventional thermal supply systems without renewable or high temperature waste heat sources. Due to economic objectives, the $\mathrm{B}$ are substituted through a combination of HP and CHP in which the CHP has a relatively low thermal efficiency compared to the B. Taking scope 2 emissions into consideration the overall emissions of IESS and DHS can be reduced by $25 \%$ and $180 \%$ respectively. The operation of the HTS allows the substitution of heatonly B through an beneficial HP and CHP. Especially the increased utilization of the CHP including the feed-in into the electric grid positively influences the scope 2 emission balance. On this basis, it should be noted that scope 2 emissions are highly dependent on the applied allocation methods as well as the structure of the regarded supply systems. The allocation method which was applied in this paper counts the avoided emissions within the electric grid towards the emissions of the CHP. Even though representing the stateof-the-art, the applied allocation method allows CHP systems to have a negative emission balance with regard to scope 2 emissions.

The presented results clarify that the operation of the HTS leads to an economic benefit by connecting an IESS and DHS in an energy flexible manner and additionally provides an ecological benefit when taking scope 2 emissions into account. Furthermore, results underline the necessity of a operational optimization due to dynamic operating as well as complex interdependencies of the heat and electricity sector. The aforementioned interdependencies may also limit the transferability of the presented results with regard to a different supply structure or temperature levels of the IESS or DHS.

\section{Conclusion}

This paper presents a data and optimization model integrated into a DT of an HTS. The HTS exchanges heat between an industrial sites' IESS and a DHS based on the techni-

Table 1 Simulation results: changes in emissions and economic benefit between baseline and optimized scenarios

\begin{tabular}{llllllllll}
\hline & \multicolumn{4}{c}{$\boldsymbol{\Delta}$ Scope $\mathbf{1}$ emissions $[\mathrm{t}]$} & \multicolumn{3}{c}{$\boldsymbol{\Delta}$ Scope $\mathbf{2}$ emissions [t] } & \multicolumn{3}{c}{$\boldsymbol{\Delta}$ Economic benefit [€] } \\
& IESS & DHS & $\boldsymbol{\Sigma}$ & IESS & DHS & $\boldsymbol{\Sigma}$ & IESS & DHS & $\boldsymbol{\Sigma}$ \\
\hline Winter & -128.7 & 170.4 & 42.1 & -112.2 & -203.9 & -316.1 & 19,386 & 1,246 & 20,632 \\
Spring & 79.7 & -74.5 & 5.2 & -126.9 & -28.5 & -155.4 & 6,912 & 2,086 & 8,998 \\
Summer & 263.5 & -225.1 & 38.4 & -249.6 & 63.4 & -186.2 & 23,668 & 3,360 & 27,028 \\
Fall & 125.2 & -116.9 & 8.3 & -158.9 & 72.1 & -231.0 & 6,436 & 4,438 & 10,874 \\
\hline
\end{tabular}


cal system presented in Kohne et al. (2021). The technical system and thus the data and optimization model integrate and extend several approaches of the related work such as:

- bidirectional heat exchange,

- integration of low exergy waste heat,

- several thermal networks of the IESS,

- sector coupling with the electric grid,

- economic and ecological objectives.

To optimize the operating behaviour of the HTS, a digital representation is integrated into the RAMI4.0 and the information, functional and business layer are further modeled. Hereby, the GDTM is transferred to the developed data and optimization model to holistically represent the energy flexibility of connecting DHS and IESS. Within the data model (information layer) different data from the surrounding systems, the energy procurement of the and the subsystems of the HTS itself are considered and processed into KPI for the optimization model. As part of a two-stage control approach (functional layer), the optimization model sets an operating schedule for a technical controller which performs the operating strategy interacting with a simulation model. The overall system design is connected to the EMS of the IESS and thus integrated into a business logic (business layer) considering economic and ecological objectives. The objectives are integrated into the data and optimization model and thus into the GDTM considering necessary information for optimized control.

To analyze the energy flexibility potential of the HTS as sector coupling system, the modules are implemented as extension to an existing optimization framework. The effects of operating the HTS supported by central modules of the DT are evaluated on one year's data of an IESS of a real industrial site. For each season (winter, spring, spring, summer, fall) different operating strategies are observable which underlines the necessity for a flexible results show a potential operating cost reduction by $6 \%$ for the IESS and increase in profits of $1.3 \%$ for the DHS. Scope 2 emissions can be reduced by $25 \%$ for the IESS and 180 \% for the DHS respectively, depending on emission factors and allocation methods.

The presented data and optimization model is developed as a proof of concept. Thus, in future work, more complex optimization models, e. g. considering temperature changes, can be integrated. Moreover, machine learning applications can be used to enhance the data model and thus optimization performance. An automated parametrization of the presented data and optimization model would facilitate the presented approach. In this work, rather conventional supply systems are analyzed which can be extended by more innovative or complex systems in the future. Similarly, different temperature levels of the IESS and DHS can be considered to assess the potential impact.

\section{Acknowledgements}

The authors gratefully acknowledge the financial support of the Project EnEff:Wärme - MeFlexWaerme by the Federal Ministry of Economic Affairs and Energy (BMWi) and the project supervision by the Projektträger Jülich (PtJ). 
writing. M. Weigold supported the presented work by supervision and funding acquisition. All authors provided feedback and helped shape the research, analysis, and manuscript. All authors read and approved the final manuscript.

\section{Funding}

Publication costs were covered by the DACH+ Energy Informatics Conference Organizers, supported by the Swiss Federal Office of Energy.

\section{Availability of data and materials}

The data sets analyzed during the current study are available from the corresponding author on reasonable request.

\section{Declarations}

\section{Competing interests}

The authors declare that they have no competing interests.

\section{Published online: 13 September 2021}

\section{References}

Ancona MA, Branchini L, Di Pietra B, Melino F, Puglisi G, Zanghirella F (2015) Utilities substations in smart district heating networks. Energy Procedia 81:597-605. https://doi.org/10.1016/j.egypro.2015.12.044

Arbeitsgemeinschaft Energiebilanzen e.V. (2020) Anwendungsbilanzen zur Energiebilanz Deutschland: Endenergieverbrauch nach Energieträgern und Anwendungszwecken, Berlin. https://ag-energiebilanzen.de/index. php?article_id=29\&fileName=ageb_19_v3.pdf

Ashtari Talkhestani B, Jung T, Lindemann B, Sahlab N, Jazdi N, Schloegl W, Weyrich M (2019) An architecture of an intelligent digital twin in a cyber-physical production system. at - Automatisierungstechnik 67(9):762-782. https:// doi.org/10.1515/auto-2019-0039

Brückner S (2016) Industrielle Abwärme in Deutschland. Technische Universität München, München

Chien KL (1972) On the automatic control of generalized passive systems. Trans Asme 74:175-185

DIN - Deutsches Institut für Normung e.V. (2016) DIN SPEC 91345:2016-04 - Referenzarchitekturmodell Industrie 4.0 (RAMI4.0). Beuth Verlag GmbH, Berlin

DIN Deutsches Institut für Normung e.V. (2018) DIN V 18599-1 - Energetische Bewertung Von Gebäuden - Berechnung des Nutz-, End- und Primärenergiebedarfs Für Heizung, Kühlung, Lüftung, Trinkwarmwasser und Beleuchtung. Berlin, Deutschland

Dong Y, Zou B (2015) A research of real-time pricing mechanism and its characteristics. J Power Energy Eng 3:240. https:// doi.org/10.4236/jpee.2015.34033

Kavvadias K, Jiménez-Navarro JP, Thomassen G (2019) Decarbonising the EU Heating Sector: Integration of the Power and Heating Sector (JRC technical reports). Publications Office of the European Union, Luxembourg

Kleinertz B, Gruber A, Veitengruber F, Kolb M, Roon S (2019) Flexibility potential of industrial thermal networks through hybridization. In: 11. Internationale Energiewirtschaftstagung (IEWT 2019). IEWT, Vienna. pp 1-31

Kohne T, Becker PA, Weber T, Panten N, Abele E (2019) Modeling approach for thermal dependencies in complex industrial energy supply system. 8th DACH+ Conference on Energy Informatics 2(S2):13-17

Kohne T, Burkhardt M, Grosch B, Feller L, Weigold M (2021) Method for continuous evaluation of industrial heating network emissions. Procedia CIRP 98. https://doi.org/10.1016/j.procir.2020.11.006.

Kohne T, Burkhardt M, Theisinger L, Weigold M (2021) Technical and digital twin concept of an industrial heat transfer station for low exergy waste heat - Manuscript submitted and accepted for publication. Proc CIRP

Kohne T, Ranzau H, Panten N, Weigold M (2020) Comparative study of algorithms for optimized control of industrial energy supply systems. Energy Inf 3(S1):1-19. https://doi.org/10.1186/s42162-020-00115-7

Lund H, Werner S, Wiltshire R, Svendsen S, Throsen J, Hvelplund F, Vad Mathiesen B (2014) 4th Generation District Heating $(4 \mathrm{GDH})$ Integrating smart thermal grids into future sustainable energy systems. Energy 68(1):1-11. https://doi.org/10. 1016/j.energy.2014.02.089.

Marguerite C, Schmidt RR, Pardo-Garcia N, Abdurafikov R (2017) Simulation based multi-criteria evaluation of design scenarios for an industrial waste heat based micro district heating network supplying standard and low-energy buildings. Energy Procedia 116:128-137. https://doi.org/10.1016/j.egypro.2017.05.061

Masson-Delmotte V, Zhai P, Pörtner H-O, Roberts D, Skea J, Shukla P. R, Pirana A, Moufouma-Ökia W, Péan C, Pidcock R, Connors S, Matthews JBR, Chen Y, Zhou X, Gomis MI, Lonnoy T, Maycock T, Tignor M, Waterfield T (2018) Global Warming of $1.5^{\circ} \mathrm{C}$.An IPCC Special Report on the impacts of global warming of $1.5^{\circ} \mathrm{C}$ above pre-industrial levels and related global greenhouse gas emission pathways, in the context of strengthening the global response to the threat of climate change, sustainable development, and efforts to eradicate poverty. IPCC. https://www.ipcc.ch/site/assets/ uploads/sites/2/2019/06/SR15_Full_Report_High_Res.pdf. in press

Pelda J, Stelter F, Holler S (2020) Potential of integrating industrial waste heat and solar thermal energy into district heating networks in germany. Energy 203:117812. https://doi.org/10.1016/j.energy.2020.117812

Pipiciello M, Caldera M, Cozzini M, Ancona MA, Melino F, Di Pietra B (2021) Experimental characterization of a prototype of bidirectional substation for district heating with thermal prosumers. Energy 223:120036. https://doi.org/10.1016/j. energy.2021.120036

Posselt G (2016) Towards Energy Transparent Factories. In: Hermann C, Kara S (eds). Sustainable Production, Life Cycle Engineering and Management. Springer, Braunschweig, Germany

Rosemann T, Löser J, Rühling K (2017) A new DH control algorithm for a combined supply and feed-in substation and testing through hardware-in-the-loop. Energy Procedia 116:416-425. https://doi.org/10.1016/j.egypro.2017.05.089

Stark R, Damerau T (2019) Digital twin. In: Chatti S, Tolio T (eds). CIRP Encyclopedia of Production Engineering. Springer, Berlin, Heidelberg. pp 1-8. https://doi.org/10.1007/978-3-642-35950-7_16870-1 
Steindl G, Stagl M, Kasper L, Kastner W, Hofmann R (2020) Generic digital twin architecture for industrial energy systems. Appl Sci 10(24):8903. https://doi.org/10.3390/app10248903

Tao F, Zhang M, Nee AYC (2019) Chapter 3 - five-dimension digital twin modeling and its key technologies. In: Tao F, Zhang M, Nee AYC (eds). Digital Twin Driven Smart Manufacturing. Elsevier Science Academic Press, San Diego, CA. pp 63-81. https://doi.org/10.1016/B978-0-12-817630-6.00003-5

Thomaßen G, Kavvadias K, Jiménez Navarro JP (2021) The decarbonisation of the EU heating sector through electrification: A parametric analysis. Energy Policy 148:111929. https://doi.org/10.1016/j.enpol.2020.111929

World Resources Institute and World Business Council for Sustainable Development (2004) The Greenhouse Gas Protocol - A Corporate Accounting and Reporting Standard, Washington DC

Zhang L, Wang Y, Feng X (2020) Design and operation optimization of industrial waste heat recovery for district heating and cooling. Chem Eng Trans 81:511-516. https://doi.org/10.3303/CET2081086

\section{Publisher's Note}

Springer Nature remains neutral with regard to jurisdictional claims in published maps and institutional affiliations.

\section{Submit your manuscript to a SpringerOpen ${ }^{\circ}$} journal and benefit from:

- Convenient online submission

- Rigorous peer review

- Open access: articles freely available online

- High visibility within the field

- Retaining the copyright to your article

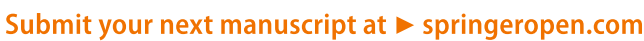

